\section{(6) OPEN ACCESS}

\title{
Client-perpetrated and husband-perpetrated violence among female sex workers in Andhra Pradesh, India: HIV/STI risk across personal and work contexts
}

\author{
Elizabeth Reed, ${ }^{1}$ J T Erausquin, ${ }^{2}$ Allison K Groves, ${ }^{3}$ Marissa Salazar, ${ }^{1}$ \\ Monica Biradavolu, ${ }^{3}$ Kim M Blankenship ${ }^{3}$
}

- Additional material is published online only. To view please visit the journal online (http://dx.doi.org/10.1136/ sextrans-2015-052162).

${ }^{1}$ Division of Global Public Health, School of Medicine: La Jolla, University of California, San Diego, CA, USA ${ }^{2}$ Department of Public Health Education, University of North Carolina, Greensboro, Greensboro, NC, USA ${ }^{3}$ Department of Sociology, American University, Washington DC, USA

\section{Correspondence to}

Dr Elizabeth Reed, Department of Medicine, Division of Global Public Health, University of California, San Diego, 9500 Gilman Drive, Mail Code 0507, La Jolla, CA 90037, USA; elizared7@gmail.com

Received 15 May 2015 Revised 13 January 2016 Accepted 1 February 2016 Published Online First 23 February 2016

\begin{abstract}
Objectives This study examines violence experienced in work and personal contexts and relation to HIV risk factors in these contexts among female sex workers (FSW) in Andhra Pradesh, India.
\end{abstract}

Methods FSW at least 18 years of age $(n=2335)$ were recruited through three rounds of respondent-driven sampling between 2006 and 2010 for a survey on HIV risk. Using crude and adjusted logistic regression models, any sexual/physical violence (last 6 months) perpetrated by clients and husbands were separately assessed in association with accepting more money for sex without a condom (last 30 days), consistent condom use with clients and husbands (last 30 days), and sexually transmitted infection (STI) symptoms (last 6 months). Results The mean age among participants was 32, $22 \%$ reported being currently married, and $22 \%$ and $21 \%$ reported physical/sexual violence by clients and husbands, respectively. In adjusted logistic regression models, FSW who experienced client violence were more likely to report accepting more money for unprotected sex trades (adjusted OR (AOR)=1.7; 95\% Cl 1.4 to 2.2), less likely to report consistent condom use with clients ( $A O R=0.6 ; 95 \% \mathrm{Cl} 0.5$ to 0.7 ) and more likely to report STI symptoms (AOR=3.5; 95\% Cl 2.6 to 4.6). Women who reported husband violence were more likely to report accepting more money for unprotected sex trades ( $A O R=2.1 ; 95 \% \mathrm{Cl} 1.2$ to 3.7), less likely to report consistent condom use with clients $(A O R=0.5 ; 95 \% \mathrm{Cl}$ 0.3 to 0.8 ) and more likely to report STI symptoms $(\mathrm{AOR}=2.6 ; 95 \% \mathrm{Cl} 1.6$ to 4.1$)$.

Conclusions Among FSW, experiences of violence in work and personal contexts are associated with sexual HIV risk behaviours with clients as well as STI symptoms.

\section{INTRODUCTION}

In India, 2.4 million people are estimated to be living with HIV. ${ }^{12}$ While HIV prevalence is $0.25 \%$ among women in India, the prevalence among female sex workers (FSW) has been estimated at $5 \%,{ }^{34}$ and as high as 55\% in select regions. ${ }^{56}$ The southern Indian state of Andhra Pradesh is among the Indian states with the highest rates of HIV; FSW are among the groups largely affected in this region. $^{7}$

Increasingly, research among FSW in India has focused on factors that challenge women's ability to engage in sexual behaviours protective of HIV. One such factor is violence. FSW in India and globally experience various forms of violence (eg, perpetrated by police, clients and non-paying relationship partners). ${ }^{2}{ }^{8-12}$ Sexual violence has been documented to increase HIV risk because perpetrators are not likely to use condoms, ${ }^{13} 14$ and also because such violence is likely to result in lacerations and vaginal trauma. ${ }^{2} 1516$ Additionally, previous studies have reported clients' use of violence and threats of violence as a way to demand having sex without a condom. ${ }^{17} 18$

The majority of this previous work among FSW has focused on physical and sexual violence from clients and/or police and the relation of such violence to condom use during sex trades. Despite high levels of violence perpetrated by noncommercial relationship partners, including husbands, ${ }^{19} 20$ among FSW, the effects of such violence have primarily been discussed in terms of women's HIV risk behaviours with these same noncommercial partners/husbands-not in relation to women's condom use with clients. It has been very well documented in studies among other populations that women who have histories of partner violence or sexual abuse are less likely to use condoms with subsequent relationship partners, potentially as a result of lower perceptions of condom negotiating power in sexual relations. ${ }^{21-23}$ Such findings could have implications for FSW, for example, regarding whether experiencing violence in one's personal life may affect condom use in the context of sex trades. Furthermore, an increasing number of studies have indicated that vulnerabilities within the personal lives of FSW (eg, high levels of responsibility in the caretaking of children, housing instability, high levels of mobility, economic debt and financial dependence) ${ }^{24-28}$ may increase the urgency of women's work, thereby increasing women's sexual HIV risk behaviours and likelihood of sexually transmitted diseases (STIs). Given the high proportions of FSW experiencing violence from husbands or non-paying intimate partners in other settings, ${ }^{19}{ }^{20}$ it is important to better understand both women's experiences of partner violence and its potential impact on HIV risk behaviours with both relationship partners and clients in Andhra Pradesh. Thus, more work is needed to understand how experiences of violence 
across personal and work-related contexts of women's lives may each contribute to HIV risk among FSW.

The primary objective of the current study is to examine violence experienced in both work (eg, by clients) and personal (eg, by husbands) contexts and relation to HIV risk factors in these contexts, including whether violence experienced in one context (eg, personal) is associated with HIV risk factors in another context (eg, work) among FSW in Andhra Pradesh, India.

\section{METHODS}

\section{Procedure and sample}

Quantitative data are from the three rounds of cross-sectional survey data collected among FSW between 2006 and 2010. Data collection was part of the Project Parivartan, which aims to evaluate the impact of a community mobilisation intervention on HIV risk among FSW in Rajahmundry, an area in the East Godavari District of Andhra Pradesh, India. Eligible participants were at least 18 years of age, female and reported having sex in exchange for money in the year prior to the survey. For each of three rounds of data collection (2006, 2007 and 2009-2010), participants were recruited via respondent-driven sampling (RDS). Specific RDS recruitment procedures are described in greater detail in our previous work. ${ }^{27}$ The RDS recruitment process continued until the predetermined sample sizes were met. Among FSW who received coupons and came to take the survey, few were ineligible (less than 5\%) in each round of data collection. Furthermore, we had a high number of recruitment waves for each round of data collection, indicating that the samples from each round were adequate in representing the underlying population of FSW in this region. ${ }^{29} 30$ We describe the sampling strategy and survey development in more detail in our previous work. ${ }^{24-28}$

Trained female Telugu-speaking research assistants obtained informed consent and administered the 90-120 min surveys in Telugu in a private Project Parivartan field office. Upon completion of surveys, participants were provided 200 rupees (approximately US\$4.70) as compensation for their time and transportation costs, as well as an additional incentive for each coupon that resulted in new study participants. Participants were offered referrals and accompaniment to relevant local support services as needed. This research was approved by the Human Research Protections Programme at the University of California (protocol \#131057), as well as the Institutional Review Boards at American University, Duke University, Yale University, and the VHS-YRG Care Medical Centre Institutional Review Board in Chennai, India. A total of $812 \mathrm{FSW}$ in round I, 673 in round II and 850 in round III gave informed consent and completed the survey. No participants were missing data on the sexual risk outcome variables and, therefore, all were included in the current analysis.

\section{Quantitative measures}

Demographic variables

Age was measured as a continuous variable. Marital status (whether report being currently married), children (any, under age 5 , between the ages of 5 and 18) and the venue in which they worked (brothel, street, lodge or hotel, home, highway or other) were also assessed.

\section{Violence}

Physical violence (last 6 months) was measured by combining two items; participants were grouped as experiencing physical violence if they responded positively to either (1) experiencing being beaten (eg, hit, slapped, pushed, kicked, punched, choked or burned) or (2) threatened with a knife, gun or other weapon, or had a weapon used against them. Sexual Violence (last 6 months) was measured by asking participants whether anyone forced them to have vaginal, anal or oral sex against their will in the last 6 months (yes/no). Women were also asked to identify the perpetrator of each type of violence (client, husband, relationship partner, police, stranger).

\section{Sources of HIV risk}

Accepting more money for sex without a condom was measured by asking participants whether this happened in the last 30 days (yes/no). Consistent condom use was measured by asking participants how often they used condoms with clients in the last 30 days; participants who reported 'always' using condoms with clients were categorised as consistent condom users. Participants were asked the same set of questions regarding their condom use with husbands. Participants were grouped as experiencing STI symptoms in the 6 months prior to the survey if they reported experiencing any of the following symptoms: lower abdominal pain not related to diarrhoea or menses, foul smelling vaginal discharge, burning while urinating, genital ulcers/ sores, swelling in groin area, itching.

\section{Data analyses}

Frequencies were assessed for sample characteristics and reports of physical and sexual violence by clients and husbands. Given the similar patterns in the data in relation to the outcome variables, experiences of any physical and/or sexual violence were combined into one variable for each perpetrator type. Due to small numbers reporting non-marital relationship violence $(6 \%$ reporting physical violence and $1 \%$ reporting sexual violence perpetration) as well as police and stranger violence (all under $5 \%$, analyses were restricted to violence perpetrated by husbands and clients. Logistic regression models were used to assess any physical and/or sexual violence in relation to accepting more money for unprotected sex trades, consistent condom use with clients, consistent condom use with husbands and STI symptoms. Separate models were constructed for assessing the influence of violence perpetrated by clients and violence perpetrated by husbands on these HIV risk-related variables. Sample characteristics associated with physical or sexual violence in bivariate analyses at $\mathrm{p}<0.05$ were included in adjusted models. Adjustments were also made to consider correlations between these different types of violence perpetrated (eg, models assessing client-perpetrated violence were adjusted for husbandperpetrated violence). ORs are presented with associated 95\% CIs, and significance of individual variables was evaluated using Wald $\chi^{2}$ tests. All analyses were conducted using SAS V.9.1 (SAS Institute, Cary, North Carolina, USA).

\section{RESULTS}

\section{Sample characteristics}

The mean age of women in the sample was $32(\mathrm{SD}=8.2)$, and $78 \%$ were under the age of 40 . Most women (86\%) had less than a high school education and $22 \%$ reported being currently married. The majority of women $(90 \%)$ report having at least one child. Women work in various types of venues, including at home $(25 \%)$, on the highway (19\%), street (11\%), lodge or hotel (7\%) and brothels (4\%) (table 1). A detailed description of sample characteristics by study wave has been provided in our previous work. $^{30}$

Women who reported experiencing client violence or husband violence were more likely to be in younger age categories compared with women not experiencing these forms of 
Table 1 Sample characteristics: total and by reported client and husband violence $(N=2336)$

\begin{tabular}{|c|c|c|c|c|c|}
\hline Variable & $\begin{array}{l}\text { Total sample }(\mathrm{N}=2335) \\
\%(\mathrm{n})\end{array}$ & $\begin{array}{l}\text { Client violence } \\
n=520(80.4 \%) \\
\%(n)\end{array}$ & $\begin{array}{l}\text { No client violence } \\
n=1816(19.6 \%) \\
\%(n)\end{array}$ & $\begin{array}{l}\text { Husband violence } \\
n=110(80.4 \%) \\
\%(n)\end{array}$ & $\begin{array}{l}\text { No husband violence } \\
\mathrm{n}=405(80.4 \%) \\
\% \text { (n) }\end{array}$ \\
\hline \multicolumn{6}{|l|}{ Age } \\
\hline 18-24 years & $15.8(370)$ & $18.9(98)$ & $15.0(272)$ & $19.1(21)$ & $13.1(53)$ \\
\hline $25-29$ years & $21.5(501)$ & $21.9(114)$ & $21.3(387)$ & $28.2(31)$ & $20.7(84)$ \\
\hline $30-34$ years & $18.4(429)$ & $19.8(103)$ & $18.0(326)$ & $20.2(22)$ & $19.5(79)$ \\
\hline $35-39$ years & $22.1(515)$ & $22.1(115)$ & $22.0(400)$ & $24.6(27)$ & $23.7(96)$ \\
\hline 40 and older & $22.3(521)$ & $\begin{array}{l}17.3(90) \\
\chi^{2}=12.1 ; p=0.01\end{array}$ & $23.7(431)$ & $\begin{array}{l}8.2(9) \\
\chi^{2}=13.9 ; p=0.0076\end{array}$ & $23.0(93)$ \\
\hline \multicolumn{6}{|l|}{ Education } \\
\hline Less than high school & 86.3 (2006) & 84.6 (438) & 86.8 (1568) & 89.8 (97) & $80.2(323)$ \\
\hline High school & $13.0(303)$ & $15.1(78)$ & $12.5(225)$ & $10.2(11)$ & $19.4(78)$ \\
\hline College or technical training & $0.7(15)$ & $\begin{array}{l}13.3(2) \\
\chi^{2}=3.0 ; p=0.22\end{array}$ & $0.7(13)$ & $\begin{array}{c}0(0) \\
\chi^{2}=5.6 ; p=0.06\end{array}$ & $0.5(2)$ \\
\hline \multicolumn{6}{|l|}{ Married } \\
\hline Yes & $22.0(515)$ & $19.1(99)$ & $22.9(416)$ & - & - \\
\hline No & $78.0(1821)$ & $\begin{array}{l}80.1(421) \\
\chi^{2}=3.5 ; p=0.06\end{array}$ & $77.1(1400)$ & - & - \\
\hline \multicolumn{6}{|l|}{ Children } \\
\hline Yes & $89.9(2100)$ & $90.0(468)$ & $89.9(1632)$ & $94.6(104)$ & $91.4(370)$ \\
\hline No & $10.1(236)$ & $\begin{array}{l}10.0(52) \\
\chi^{2}=0.07 ; p=0.93\end{array}$ & $10.1(184)$ & $\begin{array}{l}5.5(6) \\
\chi^{2}=1.2 ; p=0.27\end{array}$ & $8.6(35)$ \\
\hline \multicolumn{6}{|l|}{ Venue of workt } \\
\hline Home-based & $25.1(586)$ & $25.7(466)$ & $23.1(120)$ & $17.3(19)$ & $20.3(82)$ \\
\hline Highway-based & $19.1(445)$ & $26.0(135)$ & $17.1(310)$ & $11.8(13)$ & $12.1(49)$ \\
\hline Street-based & $11.0(256)$ & $9.4(49)$ & $11.4(207)$ & $8.2(9)$ & $8.4(34)$ \\
\hline Brothel-based & $6.7(156)$ & $9.0(47)$ & $6.0(109)$ & $14.6(16)$ & $6.7(27)$ \\
\hline Lodge & $3.9(90)$ & $5.8(30)$ & $3.3(60)$ & $3.6(4)$ & $3.0(12)$ \\
\hline Agricultural field & $15.8(368)$ & $13.7(71)$ & $16.4(207)$ & $17.3(19)$ & $25.1(101)$ \\
\hline Other & $18.9(428)$ & $\begin{array}{l}12.7(66) \\
\chi^{2}=44.7 ; p<0.001\end{array}$ & $20.0(362)$ & $\begin{array}{l}27.3(30) \\
\chi^{2}=9.4 ; p=0.15\end{array}$ & $24.3(98)$ \\
\hline
\end{tabular}

Numbers may not add up to $100 \%$ due to missing data.

tNumbers may exceed $100 \%$; categories are not mutually exclusive.

violence $(\mathrm{p}=0.01$ and $\mathrm{p}=0.0076$, respectively) (table 1$)$. Women who reported violence from husbands were more likely to report less than a high school education compared with those not reporting such violence; however, this was of borderline significance $(p=0.06)$. Women who reported violence from clients were more likely to be married compared with those not reporting such violence; however, this was of borderline significance $(p=0.06)$. Different types of venues were also associated with greater reports of client violence as well (particularly highway, brothel and hotel/lodge-based venues) $(\mathrm{p}<0.0001)$.

\section{Physical and sexual violence by perpetrator type and HIV risk factors}

Overall, 29\% reported physical violence (any perpetrator) and $16 \%$ reported sexual violence (any perpetrator) (not reported in table). Violence was most commonly reported to be perpetrated by clients and husbands; $22 \%$ and $21 \%$ reported physical or sexual violence by clients and husbands, respectively. Physical violence perpetrated by husbands was the most common form of violence reported (21\%). Physical violence perpetrated by clients $(13 \%)$ was also common in this sample (table 2). Sexual violence perpetrated by husbands was reported to be less common (1\%); however, $13 \%$ reported sexual violence perpetrated by clients.

Accepting more money for sex with no condom used was reported by $16 \%$. Consistent condom use (last 30 days) among clients was reported by 56\%; however, consistent condom use among husbands was reported by $11 \%$. Almost one half $(48 \%)$ reported having an STI symptom in the previous 6 months (table 3).

Client-perpetrated and husband-perpetrated violence and relation to risk factors for HIV: findings from crude and adjusted logistic regression models

In logistic regression models adjusted for demographics and other forms of violence perpetration, women who reported

Table 2 Violence type and perpetrator (previous 6 months) $(n=2336)$

\begin{tabular}{llll}
\hline Perpetrator & $\begin{array}{l}\text { Physical } \\
\text { violence \% (n) }\end{array}$ & $\begin{array}{l}\text { Sexual } \\
\text { violence \% (n) }\end{array}$ & $\begin{array}{l}\text { Any physical or } \\
\text { sexual violence \% (n) }\end{array}$ \\
\hline $\begin{array}{l}\text { Client } \\
\text { Yes }\end{array}$ & $13.1(307)$ & $13.1(307)$ & $22.3(520)$ \\
No & $86.9(2029)$ & $86.9(2029)$ & $77.7(1816)$ \\
Husband $(n=515)^{*}$ & & \\
Yes & $20.8(107)$ & $1.0(5)$ & $21.4(110)$ \\
No & $79.2(408)$ & $99.0(510)$ & $78.6(405)$ \\
\hline
\end{tabular}

${ }^{*}$ Among those who report having husbands. 
Table 3 Violence from clients and husbands: relation to sexual risk factors for HIV ( $n=2336$ )

\begin{tabular}{|c|c|c|c|c|}
\hline $\begin{array}{l}\text { Violence by perpetrator type } \\
\text { (independent variable in all models) }\end{array}$ & $\begin{array}{l}\text { More money for sex } \\
\text { with no condom, last } \\
30 \text { days } 15.6 \%(n=365)\end{array}$ & $\begin{array}{l}\text { Consistent condom use } \\
\text { with clients, last } 30 \text { days } \\
56.6 \%(n=1323)\end{array}$ & $\begin{array}{l}\text { Consistent condom use } \\
\text { with husbands/partners, } \\
\text { last } 30 \text { days } 10.7 \%(n=55)^{*}\end{array}$ & $\begin{array}{l}\text { STI symptom, } \\
\text { last } 6 \text { months } \\
47.6 \%(n=1113) \\
\text { OR }(95 \% \mathrm{Cl})\end{array}$ \\
\hline \multicolumn{5}{|l|}{ Client-perpetrated violence } \\
\hline \multicolumn{5}{|l|}{ Yes } \\
\hline Crude & $1.7(1.4$ to 2.3$) \dagger$ & $0.6(0.5$ to 0.8$) \dagger$ & $1.0(0.5$ to 2.0$)$ & $2.9(2.3$ to 3.6$) \dagger$ \\
\hline Adjusted $\ddagger$ & $1.7(1.4$ to 2.2$) \dagger$ & $0.6(0.5$ to 0.7$) \dagger$ & $0.9(0.4$ to 2.0$)$ & $2.9(2.3$ to 3.6$) \dagger$ \\
\hline No & 1.0 (referent) & 1.0 (referent) & 1.0 (referent) & 1.0 (referent) \\
\hline \multicolumn{5}{|l|}{ Husband-perpetrated violence§ } \\
\hline \multicolumn{5}{|l|}{ Yes } \\
\hline Crude & 1.9 (1.1 to 3.1$)$ १ & 0.5 (0.3 to 0.8$)$ १ & 0.7 (0.3 to 1.6$)$ & $2.4(1.5 \text { to } 3.8)^{* *}$ \\
\hline Adjusted $\ddagger$ & $2.1(1.2$ to 3.7$)$ १ & $0.5(0.3$ to 0.8$)$ १ & $0.8(0.3$ to 1.8$)$ & $2.6(1.6$ to 4.1$) \dagger$ \\
\hline No & 1.0 (referent) & 1.0 (referent) & 1.0 (referent) & 1.0 (referent) \\
\hline \multicolumn{5}{|c|}{$\begin{array}{l}\text { *Analyses restricted to those reporting having sex with husbands in the last } 30 \text { days }(n=325) \text {. } \\
\ddagger \text { Adjusted logistic regression models adjusted for age, venue, study round and other violence (eg, models assessing client-perpetrated violence are adjusted for husband-perpetrated } \\
\text { violence). } \\
\S \text { Analyses restricted to those reporting husbands ( } n=515) \text {. } \\
\text { Ip }<0.05 \text {, Wald. } \\
{ }_{* \star} p<0.001 \text {. } \\
+p<0.0001 \text {. }\end{array}$} \\
\hline
\end{tabular}

physical and sexual violence perpetrated by clients were more likely to report accepting more money for unprotected sex trades (last 30 days) (adjusted OR $(\mathrm{AOR})=1.7 ; 95 \%$ CI 1.4 to 2.2), less likely to report consistent condom use with clients (last 30 days) $(\mathrm{AOR}=0.6 ; 95 \% \mathrm{CI} 0.5$ to 0.7$)$ and more likely to report STI symptoms (last 6 months) (AOR $=3.5$; 95\% CI 2.6 to 4.6). Women who reported physical and sexual violence perpetrated by husbands were also more likely to report accepting more money from clients for unprotected sex trades (last 30 days) ( $\mathrm{AOR}=2.1 ; 95 \% \mathrm{CI} 1.2$ to 3.7 ), less likely to report consistent condom use with clients (last 30 days) ( $\mathrm{AOR}=0.5$; 95\% CI 0.3 to 0.8 ) and more likely to report STI symptoms (last 6 months) (AOR $=2.6$; 95\% CI 1.6 to 4.1). Crude logistic regression models produced similar findings. There were no significant findings between client-perpetrated or husbandperpetrated violence and consistent condom use with husbands (table 3).

\section{DISCUSSION}

Our findings highlight the extent and varying forms of violence within the lives of FSW as well as the impact of this violence on HIV risk. Most noteworthy, this is the first research study among FSW, to our knowledge, to indicate that violence perpetrated by husbands is associated with reduced condom use with clients, including accepting more money for sex without a condom.

Present study findings build on a number of studies documenting the link between experiences of violence among FSW and increased STI and sexual risk behaviours for HIV. ${ }^{\mathrm{W} 1-\mathrm{W} 12}$ This previous work has primarily focused on the association between violence perpetrated by non-commercial partners or clients and unprotected sex within these same partner types. ${ }^{\text {W1-W3 }}$ Not reported in this previous work, our findings specifically document that violence perpetrated by husbands appears to be associated with women's non-condom use with clients. Findings of the present study are supported by previous work indicating that a number of aspects related to women's personal lives (eg, economic vulnerability, high levels of responsibility in the caretaking of children, housing instability, mobility) appear to increase the urgency of women's work, thereby increasing women's sexual HIV risk behaviours and likelihood of having an STI. ${ }^{24-28}$

Regarding possible mechanisms through which husbandperpetrated violence may produce reduced condom use with clients, previous studies have documented that some noncommercial male partners of FSW (including husbands) may become involved with women's sex trades as a broker, and have forced women to have sex with clients without using condoms for greater financial returns. ${ }^{\text {W6-W } 14}$ Violence perpetrated by husbands may also reduce women's perceptions regarding their condom negotiating power in the context of sex trades with clients, or affect the urgency of women's work in other ways. Furthermore, reduced perception of condom and sexual negotiating power has been well documented in previous works among other populations of women who have histories of partner violence or sexual abuse. ${ }^{21-23}$

The link between client-perpetrated and husband-perpetrated violence and accepting more money for sex trades without a condom provides some evidence of the possible contribution of economic factors in explaining the association between victimisation and increased HIV risk behaviours (eg, non-condom use during sex trades with clients to make more money). Notably, we conducted exploratory analyses to assess whether women's reports of economic debt mediated the relation between violence and HIV risk factors, but we did not find a significant effect. However, other types of economic vulnerability may be more important than debt in contributing to the association between violence and HIV risk among FSW. Future studies are needed that consider other types of economic vulnerability to better understand whether experiences of client-perpetrated and/or husband-perpetrated violence create increased economic vulnerability among FSW, which in turn limit condom negotiating power with clients.

Findings of the present study are also consistent with the previous literature documenting the low rates of condom use with husbands of FSW. Condom use has been shown across multiple studies to be infrequent among non-commercial partners, often as a way to establish trust and intimacy. W1 W7-W9 
We did not find an association between violence perpetrated by husbands and condom use with husbands; this may likely be related to the high rates of inconsistent condom use with husbands (89\%). While we found an association between experiencing violence from husbands and STI symptoms, there was not a significant association between husband-perpetrated violence and non-condom use with husbands. Thus, our findings suggest that increased STIs related to violence from husbands might be partially explained by increased non-condom use with clients among women experiencing violence from husbands. While more work is needed to better understand the mechanisms explaining these findings, this finding is new to the literature.

Consistent with previous research, the current study found that FSW experienced high rates of both physical and sexual violence, from both commercial and non-commercial partners $^{12} \mathrm{w} 14$. However, the prevalence of physical and sexual violence across studies varies considerably, often due to varying measures and whether the definition was limited to specific perpetrator types or based on different time periods measured (recent vs ever). ${ }^{\mathrm{W} 2}$ W5 Furthermore, the under-reporting of violence due to high levels of associated stigma ${ }^{\mathrm{W} 13-\mathrm{W} 15}$ may vary by population, and be of particular relevance in more rural contexts such as Rajahmundry, Andhra Pradesh where the current study was conducted.

The findings of this study must be considered with recognition of several limitations. The cross-sectional design does not establish the temporality of these associations; however, our findings build on previous work linking victimisation to subsequent non-condom use, including findings from longitudinal studies. Additionally, stigma can often result in under-reporting of sensitive issues or socially undesirable behaviours, such as violence and non-condom use. ${ }^{\mathrm{W} 13-\mathrm{W} 15}$ Such under-reporting would decrease power to detect an association between violence and non-condom use. The current study found multiple strong links among these factors. Because violence perpetrated by nonmarital male partners was reported in low proportions, we did not have sufficient sample size to examine whether violence perpetrated by these other relationship partners may also have an effect on sexual risk behaviours for HIV. Future work is needed to consider violence perpetrated by these other types of noncommercial partners. Additionally, our assessment of selfreported STI symptoms would be improved in future studies with the use of biological markers detecting STI infection. Regarding study recruitment, while RDS cannot guarantee a sample truly representative of the underlying population, previous studies have found RDS to be an effective method for sampling 'hard to reach' populations, including $\mathrm{FSW}^{3-6}$ Furthermore, the current study findings are most applicable to FSW in Rajahmundry, Andhra Pradesh and may not be generalisable to populations of FSW elsewhere.

These limitations notwithstanding, we document the high prevalence of violence among FSW in this South Indian context, as well as the implications of such violence on women's risk for HIV. Present study findings highlight that experiences of violence in work and personal contexts are associated with sexual HIV risk behaviours with clients as well as STI symptoms. Thus, efforts are needed to address multiple forms of violence and perpetrators of violence in order to maximise HIV/STI prevention benefits. Notably, violence in itself (independent of any associations it may have with HIV/AIDS or other health outcomes) is a critical health and human rights issue affecting FSW across multiple domains in their lives.

\section{Key messages}

- Violence is a major contributing factor to HIV risk among female sex workers (FSW).

- Violence experienced from husbands is associated with HIV risk behaviours in the exchange of sex at work.

- Contextual-level HIV prevention strategies are needed to address multiple forms of violence and perpetrators of violence.

\section{Handling editor Jackie A Cassell}

Acknowledgements The authors wish to thank all the women who participated in the cross-sectional survey, the Rajahmundry NGO CARE-Saksham and Project Parivartan team members in India and the USA.

Contributors ER conceptualised the research questions, conducted data analysis and was involved in writing the manuscript. JTE contributed to the conceptualisation of the project, data analysis and was involved in writing and revising the manuscript. AKG contributed to the writing of the discussion section and revising of the manuscript. MS contributed to the writing of the discussion section and revising of the manuscript. Monica Biradavolu contributed to data analysis, writing and revising the manuscript. KMB contributed to the conceptualisation of the project and was involved in the writing and revising of the manuscript.

Funding This work was supported by the Bill \& Melinda Gates Foundation through Avahan, the India AIDS Initiative (Grant \# 30183). The views expressed herein are those of the authors and do not necessarily reflect the official policy or position of the Bill \& Melinda Gates Foundation and Avahan. E. Reed was also supported by a grant from the National Institute of Mental Health (K01MH099969, PI:Reed). J.T. Erausquin was supported by NIMHD P20MD002289 (PI: Wallace).

\section{Competing interests: None declared.}

Ethics approval This research was approved by the Institutional Review Boards at the University of California San Diego (Protocol \# 131057), American University and at Duke University, the Human Investigations Committee at Yale University, and the VHS-YRG Care Medical Centre Institutional Review Board in Chennai, India.

Provenance and peer review Not commissioned; externally peer reviewed.

Data sharing statement Data are not yet available publicly, but can be requested via an email to the PI.

Open Access This is an Open Access article distributed in accordance with the terms of the Creative Commons Attribution (CC BY 4.0) license, which permits others to distribute, remix, adapt and build upon this work, for commercial use, provided the original work is properly cited. See: http://creativecommons.org/ licenses/by/4.0/

\section{REFERENCES}

1 National AIDS Control Organization (NACO), Government of India (2010). Ministry of Health \& Family Welfare Department of AIDS Control. http://www.nacoonline.org/ upload/HomePage/NACO $\% 2$ Press $\% 20$ Release $\% 20$ on $\% 20$ HIV\%20Estimates.pdf (retrieved 28 February 2011).

2 UNAIDS. UNAIDS report on the global AIDS epidemic. Geneva: UNAIDS, 2010.

$3 \mathrm{Ng} \mathrm{M}$, Gakidou E, Levin-Rector A, et al. Assessment of population-level effect of Avahan, an HIV-prevention initiative in India. Lancet 2011;378:1643-52.

4 Ramesh BM, Moses S, Washington R, et al. Determinants of HIV prevalence among female sex workers in four south Indian states: analysis of cross-sectional surveys in twenty-three districts. AIDS 2008;22(Suppl 5):S35-44.

5 Radhika Brahme M, Mehta S, Sahay S, et al. Correlates and trend of HIV prevalence among female sex workers attending sexually transmitted disease clinics in Pune, India (1993-2002). J Acquir Immune Defic Syndr 2006;41:107-13.

6 Chandrasekaran P, Dallabetta G, Loo V, et al. Containing HIVIAIDS in India: the unfinished agenda. Lancet Inf Dis 2006;6:508-21.

7 World Bank. Third National HIVIAIDS Control Project. 2013. http://www-wds. worldbank.org/external/default/WDSContentServer/WDSP/IB/2013/04/05/ 000442464_20130405104854/Rendered/PDF/ICR24370P0785300fficialOuse0 only090.pdf (accessed 5 Feb 2014).

8 Erausquin JT, Reed E, Blankenship KM. Police-related experiences and HIV risk among female sex workers in Andhra Pradesh, India. J Infect Dis 2011;204:S1223-8.

9 Pando MA, Coloccini RS, Reynaga E, et al. Violence as a barrier for HIV prevention among female sex workers in Argentina. PLOS ONE 2013;8:e54147. 
10 Swain SN, Saggurti N, Battala M, et al. Experience of violence and adverse reproductive health outcomes, HIV risks among mobile female sex workers in India. BMC Public Health 2011;11:357.

11 Beattie TS, Bhattacharjee P, Ramesh BM, et al. Violence against female sex workers in Karnataka state, south India: impact on health, and reductions in violence following an intervention program. BMC Public Health 2010;10:476.

12 Panchanadeswaran $S$, Johnson $S$, Sivaram $S$, et al. A descriptive profile of abused female sex workers in India. J Health Popul Nutr 2010:28:211-20.

13 Couture MC, Soto JC, Akom E, et al. Violence against intimate partners and associations with inconsistent condom use among clients of female sex workers in Haiti. Public Health Rep 2010;125:896-902.

14 Dunkle KL, Jewkes RK, Nduna M. Perpetration of partner violence and HIV risk behaviour among young men in the Rural Eastern Cape, South Africa. AIDS 2006;20:2107-2114.26.

15 Sarkar K, Bal B, Mukherjee R, et al. Parsons S. Sex-trafficking, violence, negotiating skill, and HIV infection in brothel-based sex workers of eastern India, adjoining Nepal, Bhutan, and Bangladesh. J Health Popul Nutr 2008;26:223-31.

16 Cler-Cunningham L, Christerson C. Studying violence to stop it. Research for Sex Work 2001:4:25-6.

17 Schunter B. Filial piety and vietnamese sex workers in Svay Pak, Cambodia. Research for Sex Work 2001;4:9-10.

18 Wojcicki JM, Malala J. Condom use, power and HIV/AIDS risk: sex-workers bargain for survival in Hillbrow/Joubert Park/Berea, Johannesburg. Soc Sci Med 2001;53:99-121.

19 El-Bassel N, Witte SS, Wada T, et al. Correlates of partner violence among female street-based sex workers: substance abuse, history of childhood abuse, and HIV risks. AIDS Patient Care STDS 2001;15:41-51.

20 Zhang $C$, Li X, Hong Y, et al. Partner violence and HIV risk among female sex workers in China. AIDS Behav. 2012;16:1020-30.
21 Hall T, Hogben M, Carlton AL, et al. Attitudes toward using condoms and condom use: difference between sexually abused and non-abused African American female adolescents. Behav Med 2008;34:45-54

22 Wingood GM, DiClemente RJ. Child sexual abuse, HIV sexual risk, and gender relations of African-American women. Am J Prev Med 1997;13:380-4.

23 Masters NT, George WH, Davis KC, et al. Women's unprotected sex intentions: roles of sexual victimization, intoxication, and partner perception. J Sex Res 2014:51:586-98.

24 Reed E, Gupta J, Biradavolu M, et al. The context of economic insecurity and relation to violence and risk factors for HIV among female sex workers in Andhra Pradesh, India. Public Health Rep 2010;125(Suppl 4):81-9.

25 Reed E, Biradavolu M, Gupta J, et al. The role of housing in determining HIV risk among female sex workers in Andhra Pradesh, India: Considering women's life contexts. Soc Sci Med 2011;72:710-16.

26 Reed E, Gupta J, Blankenship KM. Migration/Mobility and risk factors for HIV among female sex workers in Andhra Pradesh, India: Implications for HIV prevention. Int I STD AIDS 2012;23:e7-13.

27 Reed E, Silverman JG, Stein B, et al. Motherhood and HIV Risk Among Female Sex Workers in Andhra Pradesh, India: The Need to Consider Women's Life Contexts. AIDS Behav 2013;17:543-50

28 Blankenship KM, Burroway R, Reed E. Factors associated with awareness and utilization of a community mobilization intervention for female sex workers in Andhra Pradesh, India. Sex Transm Infect 2010;86(Suppl 1):i69-75.

29 Heckathorn DD. Respondent driven sampling II: deriving statistically valid population estimates from chain-referral samples of hidden populations. Soc Probl 2002:49:11-34.

30 Erausquin JT, Reed E, Blankenship KM. Change over time in police interactions and HIV risk behavior among female sex workers in Andhra Pradesh, India. AIDS Behav 2015;19:1108-15. 